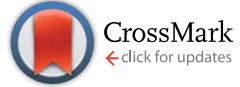

Cite this: RSC Adv., 2015, 5, 70874

Received 8th June 2015

Accepted 10th August 2015

DOI: $10.1039 / c 5 r a 10629 j$

www.rsc.org/advances

\section{Reactivity of iron-based nanoparticles by green synthesis under various atmospheres and their removal mechanism of methylene blue $\uparrow$}

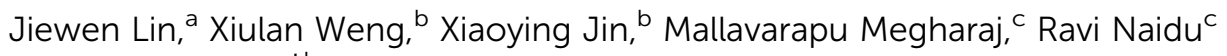 \\ and Zuliang Chen*bc
}

\begin{abstract}
In this study, iron-based nanoparticles (Fe NPs) were synthesized using tea extracts under various atmospheres $\left(\mathrm{N}_{2}, \mathrm{O}_{2}\right.$ and air) to understand how atmospheres impact on the reactivity of Fe NPs, where Fe NPs were used for the degradation of methylene blue (MB). SEM and FTIR confirmed the morphology and change in size of iron-based nanoparticles before and after reaction with $M B$, indicating that different Fe composition, morphology and size were obtained under various atmospheres resulting in different reactivity of Fe NPs. In addition, various parameters impacting on removing MB by Fe NPs synthesized under various atmospheres show that the solution $\mathrm{pH}$ significantly affects the reactivity of Fe NPs. Furthermore, the data fitted well to the pseudo-second-order adsorption and pseudo-first-order reduction models, confirming that the removal of $\mathrm{MB}$ was based on both adsorption and reduction. Langmuir and Freundlich isotherms demonstrate that the removal of MB by Fe NPs synthesized under various atmospheres was different due to their composition, morphology and size. Finally, the degraded products such as benzothiazole were identified by gas chromatography-mass spectrometry (GC-MS) after the degradation of MB, and finally a feasible removal pathway is proposed.
\end{abstract}

\section{Introduction}

Dyes are generally used in textiles, paper, tanneries and rubber manufacturing, and removing dye from discharge effluents remains a serious problem. ${ }^{1}$ The dyes such as methylene blue (MB) released into the environment may cause an increase in chemical and biological oxygen demand, and it are difficult for microbes to decompose. ${ }^{2}$ Since $\mathrm{MB}$ is a type of cationic dye with great stability, the degradation of MB by the methods such as biological, chemical precipitation and adsorption is difficult. ${ }^{3}$ Activated carbon ${ }^{4}$ and wheat shells were used to remove basic dye from aqueous solutions. ${ }^{3}$

Developments in nanotechnology have allowed iron nanoparticles (Fe NPs) to be the subject of increasing attention in the field of wastewater treatment containing dyes. The mechanisms for removing dyes and their dependence on adsorption and reduction by $\mathrm{Fe}$ NPs have been proposed. For instance, magnetic $\mathrm{Fe}_{3} \mathrm{O}_{4}$ nanoparticles were utilized for adsorption of

${ }^{a}$ School of Chemistry and Chemical Engineering, Fujian Normal University, Fuzhou 350007, Fujian Province, China

${ }^{b}$ School of Environmental Science and Engineering, Fujian Normal University, Fuzhou 350007, Fujian Province, China. E-mail: Zuliang.chen@newcastle.edu.au; Tel: +61-0249139748

'Global Centre for Environmental Remediation, University of Newcastle, Callaghan, NSW 2308, Australia

$\dagger$ Electronic supplementary information (ESI) available. See DOI: $10.1039 / \mathrm{c} 5 \mathrm{ra} 10629 \mathrm{j}$ neutral red dye from aqueous solution. ${ }^{4}$ Nanoscale zero-valent iron (nZVI) supported bentonite was used to degrade acid violet red B. ${ }^{5}$ To date, numerous methods have been developed for the synthesis of Fe NPs, and the chemical method of using sodium borohydride $\left(\mathrm{NaBH}_{4}\right)$ as a reducing agent is often employed in the synthesis of Fe NPs. Drawbacks in the chemical method include low production rates, high energy consumption, and high cost, as well as contamination arising from chemical precursors, toxicity of the used solvents and generation of hazardous by-products. ${ }^{6,7}$ In contrast, the green synthesis of metal nanoparticles using plant extracts due to the ability of polyphenols to function as natural reducing agents has been proposed as an alternative to the chemical method. ${ }^{7}$ Hence, synthesis of metal nanoparticles using plant extracts is generally cost-effective, biocompatible, non-toxic, and ecofriendly. ${ }^{6,7}$

In developing the green synthesis of Fe NPs, only a few studies have been done using plant extracts for synthesis of $\mathrm{Fe}$ NPs. Consequently, there are limitations in understanding the effect of synthetic conditions on the morphology and size distribution of Fe NPs, which involve the reactivity of Fe NPs. In this paper, iron-based nanoparticles synthesized by green tea extracts passing $\mathrm{N}_{2}, \mathrm{O}_{2}$ and air and their used for the removal of $\mathrm{MB}$ in aqueous solution were investigated. In addition, we particularly investigate the mechanism for removing MB using kinetic studies. Thus, the following aspects were done: (1) characterization of Fe NPs synthesized under $\mathrm{N}_{2}$ (N-Fe NPs), $\mathrm{O}_{2}$ 
(O-Fe NPs) and air (air-Fe NPs) before and after reaction with MB to understand their differences in morphology and size, (2) the reactivity of Fe NPs synthesized under $\mathrm{N}_{2}, \mathrm{O}_{2}$ and air by estimation of various experimental parameters affecting the removal of MB; (3) the study of adsorption and reduction kinetics to further understand the removal process of $\mathrm{MB}$ and proposing a feasible removal mechanism.

\section{Experimental}

\subsection{Preparation of Fe NPs $\left(\mathrm{N}_{2}, \mathrm{O}_{2}\right.$ and air $)$}

The extract of green tea was prepared by adding $60 \mathrm{~g}$ of processed green tea leaf into $1000 \mathrm{~mL}$ distilled water in a water bath heated at $353 \mathrm{~K}$ for $1 \mathrm{~h}$. Then the extracts were taken for vacuum filtration after cooling to room temperature. Before $0.10 \mathrm{~mol} \mathrm{~L}^{-1}$ $\mathrm{Fe}_{2} \mathrm{SO}_{4}$ was added to the tea extracts with a ratio volume of $1: 2$, we passed it into the $\mathrm{N}_{2}, \mathrm{O}_{2}$ or air and kept it in a ventilation state during the synthetic process. Following vacuum-filtration this mixture's complete reaction was taken to the vacuum drying chamber for $12 \mathrm{~h}$. Only then were these nano-solid particles used to remove MB.

\subsection{Characterization}

Scanning electron microscopy (SEM) images of GT-Fe NPs synthesized under $\mathrm{N}_{2}, \mathrm{O}_{2}$ and air before and after reaction with MB were acquired using a JSM-7500F (JEOL Ltd Co., Tokyo, Japan) to observe the surface morphology and size. The spectrum of MB, green tea extract, and Fe NPs inletting $\mathrm{N}_{2}, \mathrm{O}_{2}$ and air before and after reaction with $\mathrm{MB}$ were determined by Fourier transform infrared spectroscopy (FTIR Nicolet 5700, Thermo Corp., USA). A 1\% specimen was mixed with $100 \mathrm{mg}$ $\mathrm{KBr}$ to press into a sheer slice so that any changes in the functional groups before and after reaction could be observed.

The MB degradation products were characterized by gas chromatography-mass spectrometry (GC-MS, Thermo Corp., USA). The analytical conditions are listed as follows: ethyl acetate as solvent; capillary column $(30 \mathrm{~mm})$ as separation; helium as carrier gas and the sample volume set at $270{ }^{\circ} \mathrm{C}$. The temperature programs were determined since the initial temperature was $50{ }^{\circ} \mathrm{C}$ for $2 \mathrm{~min}$ and then programmed to increase by $30{ }^{\circ} \mathrm{C}$ per minute up to $220{ }^{\circ} \mathrm{C}$ and then hold at $220^{\circ} \mathrm{C}$ for $3 \mathrm{~min}$. Then temperature was increased up to $260^{\circ} \mathrm{C}$ by $6^{\circ} \mathrm{C}$ per minute for $10 \mathrm{~min}$ holding. The mass spectrometry starts from 20 to $600(\mathrm{~m} / \mathrm{z})$.

\subsection{Batch experiments}

To compare the removal efficiency of $\mathrm{MB}$ in aqueous solution, the degradation experiments were carried out using Fe NPs $(0.03 \mathrm{~g})$ synthesized under $\mathrm{N}_{2}, \mathrm{O}_{2}$ and air synthesized added to $30 \mathrm{~mL}$ MB at diverse conditions. Mixed solutions were stirred on a rotary shaker $(125 \mathrm{rpm})$ at $298 \mathrm{~K}$ to various time intervals, then centrifuged at $7000 \mathrm{rpm}$ for $5 \mathrm{~min}$. The influence of experiment parameters on the removing MB was investigated. For instance, dosage of Fe NPs was $0.5-2 \mathrm{~g} \mathrm{~L}^{-1}$ in this study, initial concentration of $\mathrm{MB}$ was $50-100 \mathrm{mg} \mathrm{L}^{-1}$, the reaction temperature was 298-313 K, and solutions of $\mathrm{pH}$ values ranged from 3.03-9.44.
Experiments were carried out in duplicate. The removal efficiency of MB using N-Fe NPs, O-Fe NPs and air-Fe NPs $v s$. the time $(5,10,20,30,40$, and $50 \mathrm{~min})$ at the temperature of $293 \mathrm{~K}$, $298 \mathrm{~K}, 303 \mathrm{~K}$ and $313 \mathrm{~K}$, respectively were showed in Fig. S1. $\dagger$ The various kinetic parameters were obtained from fitting the concentration of $\mathrm{MB} v s$. the time. To investigate the stability of the $\mathrm{Fe}$ NPs, the recyclable experiments were conducted at the optimum condition of $T=313 \mathrm{~K}, C_{0}=50 \mathrm{mg} \mathrm{L}^{-1}, C=1 \mathrm{~g} \mathrm{~L}^{-1}$ and $\mathrm{pH}=9.44$ for three times, and the results were showed in Fig. S2. $\dagger$

UV-visible Spectrophotometer (722 N, Shanghai, China) was used to detect the concentration of MB solution at $\lambda_{\max }=$ $665 \mathrm{~nm}$ (Fig. S3 $\dagger$ ). The efficiency in removing MB was calculated using the following equation. ${ }^{6}$

$$
\eta=\frac{C_{0}-C_{t}}{C_{0}}
$$

where $\eta(\%)$ represents the $\mathrm{MB}$ removal percentage, and $C_{0}$ and $C_{t}\left(\mathrm{mg} \mathrm{L}^{-1}\right)$ represent the concentration of $\mathrm{MB}$ at initial and $t$ time, respectively.

\section{Results and discussion}

\subsection{Characterization}

3.1.1 SEM analysis. The morphology and size of N-Fe NPs, $\mathrm{O}-\mathrm{Fe}$ NPs and air-Fe NPs are observed in Fig. 1. The images of in Fig. 1(a), (c) and (e) show Fe NPs $\left(\mathrm{N}_{2}, \mathrm{O}_{2}\right.$ and air) before reaction with $\mathrm{MB}$, respectively, which confirm that the Fe NPs have a spheroid morphology. The size of N-Fe NPs, O-Fe NPs and air-Fe NPs is $87.4,141.2$ and $117.8 \mathrm{~nm}$, respectively. This is because it is difficult to oxidize $\mathrm{Fe}^{0}$ in $\mathrm{N}_{2}$ atmosphere hence the sizes of N-Fe NPs are smallest which agrees with the following analysis of FTIR. Additionally, the images of in Fig. 1(b), (d) and (f) present Fe NPs $\left(\mathrm{N}_{2}, \mathrm{O}_{2}\right.$ and air) after reaction with MB. It can be observed that the surface of Fe NPs became scabrous when they gathered into clusters and the sizes of N-Fe NPs, O-Fe NPs and air-Fe NPs were determined as being 131.9, 271.2 and $182.4 \mathrm{~nm}$, respectively. This is due to: (1) iron oxide and hydroxide $\left(\mathrm{Fe}_{3} \mathrm{O}_{4}\right.$, $\mathrm{Fe}_{2} \mathrm{O}_{3}, \mathrm{Fe}(\mathrm{OH})_{3}$ and $\mathrm{Fe}(\mathrm{OOH})$ ) forming on the surface of Fe NPs after their reaction with $\mathrm{MB} ;{ }^{8}$ and (2) MB molecules or degraded products were adsorbed onto the Fe NPs' surface.

3.1.2 FTIR analysis. The results of FTIR are shown in Fig. 2, which represent Fe NPs $\left(\mathrm{N}_{2}, \mathrm{O}_{2}\right.$ and air) before and after reaction with $\mathrm{MB}$, green tea extract and $\mathrm{MB}$ powder. As shown in Fig. 2(a), (c) and (e), the bands around $1629 \mathrm{~cm}^{-1}$, which are attributed to the stretching vibration of the $\mathrm{C}=\mathrm{C}$ groups of organics of green tea extract, reflect the higher carbohydrate content of all the fresh Fe NPs. The band at approximately $1337 \mathrm{~cm}^{-1}$ corresponds to the asymmetric vibration of the $\mathrm{C}_{\mathrm{Ar}^{-}}$ $\mathrm{N}-\mathrm{CH}_{3}$ (ref. 9) and the band at approximately $765 \mathrm{~cm}^{-1}$ corresponds to the $\mathrm{Fe}-\mathrm{OH}$ vibration. Compared to the FTIR spectra of the fresh Fe NPs (Fig. 2(a), (c) and (e)), the change in the bands for used Fe NPs is observed in Fig. 2(b), (d) and (f). As shown in Fig. 2(b), (d) and (f), the bands at around $827 \mathrm{~cm}^{-1}$ correspond to the $=\mathrm{C}-\mathrm{H}$ plane bending vibration on benzene which were also detected in Fig. 2(h), indicating that the MB molecules were adsorbed onto the surface of Fe NPs (N-Fe NPs, O-Fe NPs and air-Fe NPs). ${ }^{9}$ 

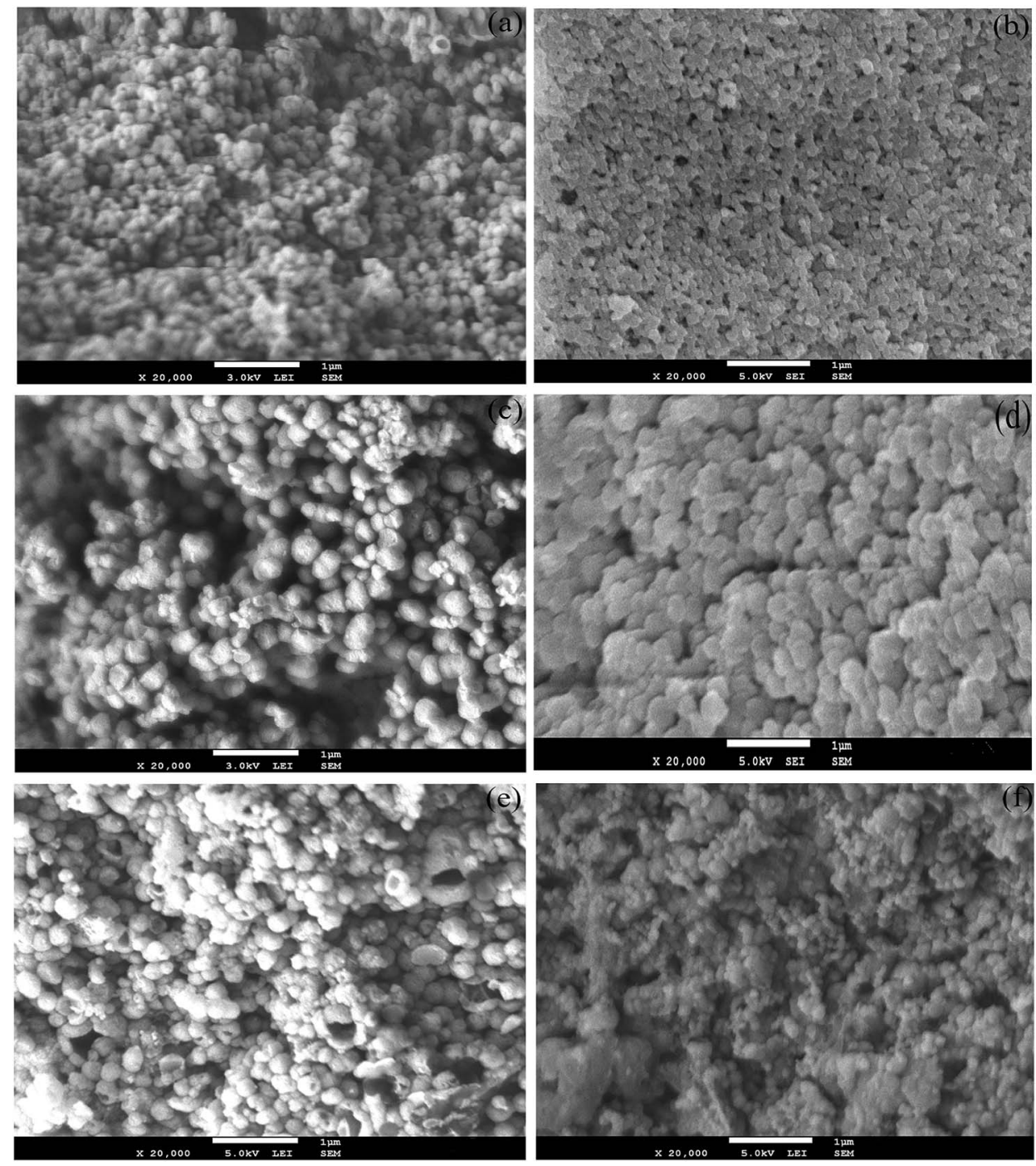

Fig. 1 SEM images of N-Fe NPs before (a) and after (b) reaction with MB; O-Fe NPs before (c) and after (d) reaction with MB; air-Fe NPs before (e) and after (f) reaction with MB.
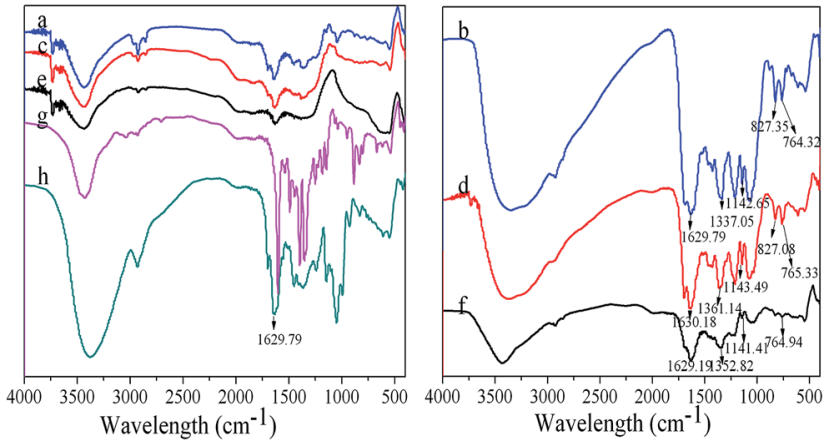

Fig. 2 FTIR spectra of N-Fe NPs before (a) and after (b) reaction with $\mathrm{MB} ; \mathrm{O}-\mathrm{Fe}$ NPs by pass before (c) and after (d) reaction with MB; air-Fe NPs by before (e) and after (f) reaction with MB; green tea extract (g); MB powder (h).

There were strong bands at $1337-1361 \mathrm{~cm}^{-1}$ referring to $\mathrm{C}_{\mathrm{Ar}}{ }^{-}$ $\mathrm{N}$ (stretching between aromatic ring and nitrogen atom) and $\mathrm{CH}_{3}$ asymmetric vibration, the $\mathrm{N}-\mathrm{CH}_{3}$ stretching at $1143 \mathrm{~cm}^{-1}$.
These were all attributable to MB or its degraded products. The bands at approximately $764 \mathrm{~cm}^{-1}$ were $\mathrm{C}-\mathrm{H}$ out of plane bending vibration on benzene, which probably corresponded to the degraded products of MB by Fe NPs. The adsorption band at $1630 \mathrm{~cm}^{-1}$ signified the $\mathrm{C}=\mathrm{C}$ stretching vibration ${ }^{9}$ and was shifted subtly to broadly imply that $\mathrm{MB}$ was most likely adsorbed onto the surface of Fe NPs $\left(\mathrm{N}_{2}, \mathrm{O}_{2}\right.$ and air).

When comparing the differences in Fig. 2(b), (d) and (f), which represents the degradation of MB by N-Fe NPs, O-Fe NPs and air-Fe NPs, respectively, the wavelength of various functional groups shifting to longer wavelength on O-Fe NPs is observed. However, the high band intensity indicates that the MB molecules are adsorbed onto the surface of Fe NPs, yet on the other hand, the degraded products reduced by Fe NPs are capped simultaneously on the surface.,8 Additionally, it emerged that the intensity of band corresponded to N-Fe NPs more strongly than the O-Fe NPs and air-Fe NPs. This is due to the fact that the MB molecules on the surface of N-Fe NPs were reduced by $\mathrm{Fe}^{0}$, resulting in the surface active sites being 
unsaturated and more MB molecules adsorbed. The mentioned above results from FIIR provide the evidence for the removal of MB based on the both adsorption and reduction. ${ }^{8}$

\subsection{The effect of various parameters on removing MB}

3.2.1 Effect of initial $\mathrm{pH}$ values. The initial $\mathrm{pH}$ value is one of the most significant parameters influencing the removal process of dyes for water treatment since the charge of surface on adsorbent and dye molecules can be influenced by $\mathrm{pH}$ values in aqueous solution. ${ }^{10,11}$ As shown in Fig. 3(a), the efficiency in removing MB by N-Fe NPs, O-Fe NPs and air-Fe NPs was improved when the $\mathrm{pH}$ range increased from 3.03 to 9.44. This is due to the surface active sites of Fe NPs $\left(\mathrm{N}_{2}, \mathrm{O}_{2}\right.$ and air $)$ transforming from positive to negative charge when $\mathrm{pH}$ increased, resulting in the presence of electrostatic attraction between the adsorbents and MB molecules since MB molecule is intrinsically cationic dyes. In contrast, $\mathrm{Fe}^{0}$ can be corroded to form maghemite $\left(\gamma-\mathrm{Fe}_{2} \mathrm{O}_{3}\right)$, magnetite $\left(\mathrm{Fe}_{3} \mathrm{O}_{4}\right)$ and iron hydroxides. ${ }^{6}$ On the other hand, we can conclude that the effect of removing MB by N-Fe NPs $(91.5 \%)$ was better than that of $\mathrm{O}-\mathrm{Fe}$ NPs $(76.6 \%)$ and air-Fe NPs $(83.9 \%)$ at $\mathrm{pH}=9.44$. The is due to the fact that $\mathrm{Fe}^{0}$ occupying most of the internal structure of N-Fe NPs while iron oxide nanoparticles occupied the main parts of the surface of both O-Fe NPs and air-Fe NPs.

3.2.2 Effect of dosage of Fe NPs. The effect of Fe NPs dosage on the removal of MB via Fe NPs $\left(\mathrm{N}_{2}, \mathrm{O}_{2}\right.$ and air) is presented in Fig. 3(b), where we can observe that increasing the amount of adsorbent (range from 0.5-2.0 $\mathrm{g} \mathrm{L}^{-1}$ ) enhanced the dye removal efficiency. This is attributed to the larger iron surface area and more available adsorption active sites..$^{10}$ Moreover, the adsorption capacity of Fe NPs increases when the absorbent dosage also increases. As shown in Fig. 3(b), when the amount of adsorbent increases to $2.0 \mathrm{~g} \mathrm{~L}^{-1}$, the removal efficiency of $\mathrm{MB}$ using Fe NPs $\left(\mathrm{N}_{2}\right.$, air and $\left.\mathrm{O}_{2}\right)$ reach $100.0 \%, 97.0 \%$ and $78.2 \%$ respectively. It can be seen that the N-Fe NPs were the most efficient in removing MB compared to the others, contributing to the presence of zero-valent iron nanoparticles. Moreover this finding is consistent with the above conclusion.

3.2.3 Effect of initial concentration of MB. The effect of initial dye concentration in solution on the efficiency in removing $\mathrm{MB}$ is documented in Fig. $3(\mathrm{c})$. As the initial $\mathrm{MB}$ concentration increases from 50 to $100 \mathrm{mg} \mathrm{L}^{-1}$, the percentage of MB removed by N-Fe NPs declines from $97.4 \%$ to $55.6 \%$, while that by O-Fe NPs slowing down markedly from $83.0 \%$ to $32.5 \%$ and that by air-Fe NPs is between them. The removal efficiency of dye decreased when dye concentration increased, because there were less available surface active sites for constant adsorbent dosage. Furthermore, mass-transfer resistance inhibited MB molecules being adsorbed onto the surface of Fe NPs from solution phase..$^{11}$ However, the presence of $\mathrm{Fe}^{0}$ in $\mathrm{N}-\mathrm{Fe}$ NPs led to the difference with O-Fe NPs and air-Fe NPs in terms of efficiently removing MB. Therefore we can conclude that N-Fe NPs are the most efficient in removing MB.

3.2.4 Effect of temperature. Temperature plays an important role in influencing the removal efficiency of adsorption and reduction process for MB by Fe NPs $\left(\mathrm{N}_{2}, \mathrm{O}_{2}\right.$ and air). The effect of reaction temperature $(293 \mathrm{~K}, 298 \mathrm{~K}, 303 \mathrm{~K}$ and $313 \mathrm{~K})$ on the removal efficiency using Fe NPs is depicted in Fig. 3(d). Here, the efficiency of N-Fe NPs in removing MB was 51.4, 87.3, 89.4
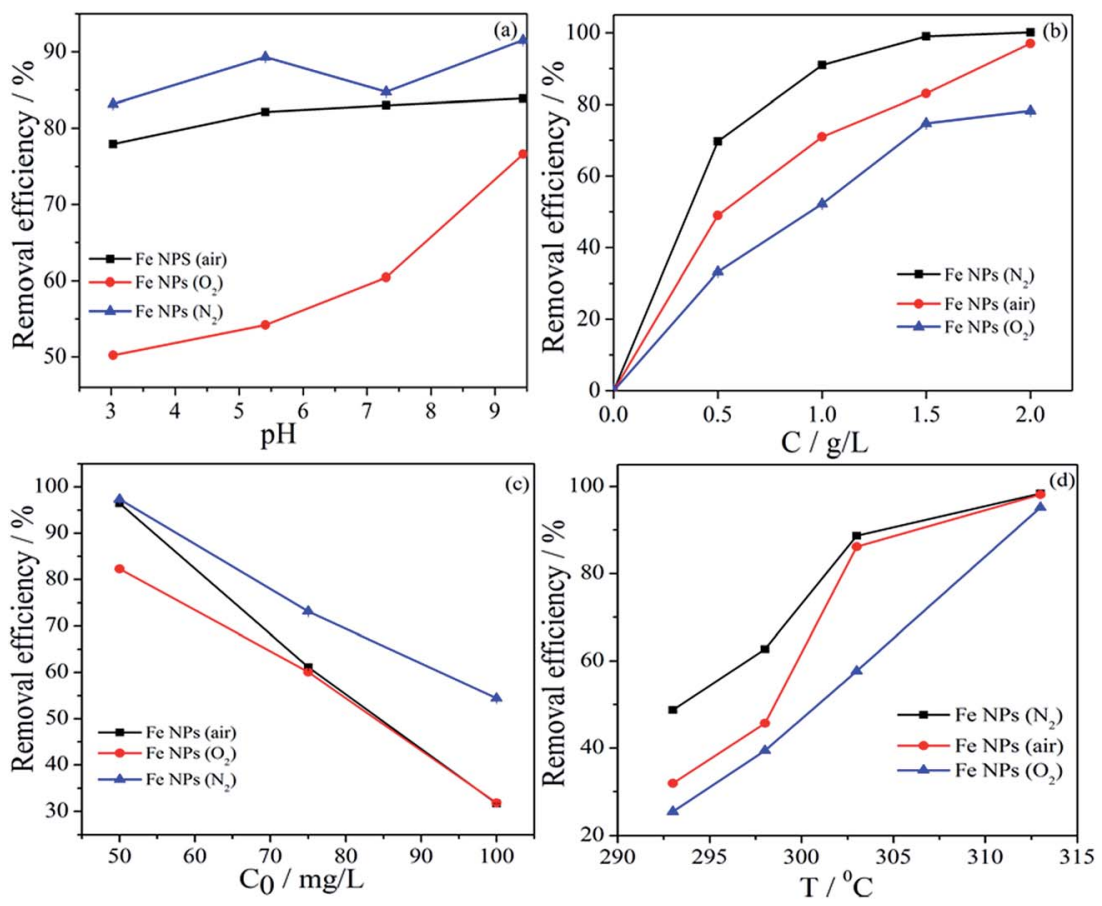

Fig. 3 Degradation of MB at experiment parameters. (a) Effect of the initial $\mathrm{pH}$ values. Condition: $1.0 \mathrm{~g} \mathrm{~L}^{-1} ; 50 \mathrm{mg} \mathrm{L}^{-1} ; 30 \mathrm{~mL}^{-1} 298 \mathrm{~K} ; 125 \mathrm{r} \mathrm{min}^{-1}$; (b) effect of dosages of Fe NPs ( $\mathrm{N}_{2}, \mathrm{O}_{2}$ and air). Condition: $\mathrm{pH}=7.3 ; 50 \mathrm{mg} \mathrm{L}^{-1} ; 30 \mathrm{~mL} ; 298 \mathrm{~K} ; 125 \mathrm{r} \mathrm{min}^{-1}$; (c) effect of initial concentration of MB. Condition: $\mathrm{pH}=7.3 ; 1.0 \mathrm{~g} \mathrm{~L}^{-1} ; 30 \mathrm{~mL} ; 298 \mathrm{~K} ; 125 \mathrm{r} \mathrm{min}^{-1}$; (d) effect of temperature. Condition: $\mathrm{pH}=7.3 ; 1.0 \mathrm{~g} \mathrm{~L}^{-1} ; 30 \mathrm{~mL}^{\circ} 50 \mathrm{mg} \mathrm{L}-1.125 \mathrm{r} \mathrm{min}^{-1}$. 
and $98.4 \%$, at temperatures of $298,293,303$ and $313 \mathrm{~K}$, respectively. It is indicated that the removal of MB by N-Fe NPs was an endothermic process. However, as shown in Fig. 3(d), the removal efficiency of MB by O-Fe NPs was 25.4, 39.5, 57.7, and $95.2 \%$ at temperatures of $293,298,303$ and $313 \mathrm{~K}$, respectively. It is suggested that the O-Fe NPs were less efficient in removing $\mathrm{MB}$ compared to N-Fe NPs because the surface of $\mathrm{O}-\mathrm{Fe}$ NPs was covered with iron oxide and hydroxide. Meanwhile, the air-Fe NPs' efficiency when removing MB was determined by the amount of nZVI and iron oxide nanoparticles these particles contained. Consequently, the efficiency in removing dyes can be boosted by raising the temperature because this serves to encourage collisions between MB molecules, which in turn lead to more activation energy. ${ }^{12}$ Homologous phenomena have been reported in some studies. ${ }^{\mathbf{1 0 , 1 3}}$ Moreover, this result agrees with the kinetic study which is reported below.

\subsection{Kinetic study}

Previous reports ${ }^{\mathbf{1 4}, \mathbf{1 5}}$ have indicated that MB removal by Fe NPs involves adsorption and reduction. However, to further confirm the removal of $\mathrm{MB}$ based on adsorption and reduction, adsorption and reduction kinetics, adsorption isotherms and thermodynamic models were used to fit the data. The amount of absorbed MB was calculated using the following formula: ${ }^{15,16}$

$$
q_{\mathrm{e}}=\frac{\left(C_{\mathrm{i}}-C_{\mathrm{e}}\right) V}{m}
$$

where $q_{\mathrm{e}}\left(\mathrm{mg} \mathrm{g}^{-1}\right)$ represents the amount of $\mathrm{MB}$ absorbed by $\mathrm{Fe}$ NPs at equilibrium, $C_{\mathrm{i}}\left(\mathrm{mg} \mathrm{L}^{-1}\right)$, the concentration of MB in solution at time $t, C_{\mathrm{e}}\left(\mathrm{mg} \mathrm{L}^{-1}\right)$, the equilibrium concentration of MB in solution, $V(\mathrm{~mL})$, the volume of MB solution used and $m$ (g) is the weight of the adsorbent used.

3.3.1 Adsorption kinetics. The adsorption of $\mathrm{MB}$ onto $\mathrm{Fe}$ NPs synthesized under various atmospheres may involve physical and chemical sorption. The dynamic process of $\mathrm{MB}$ adsorption was analyzed by using pseudo-first-order and pseudo-second-order equations, because these kinetic models are often applied to fit the process of adsorption. Pseudo-firstorder equation is described as follows: ${ }^{17}$

$$
\ln \left(q_{\mathrm{e}}-q_{t}\right)=\ln q_{\mathrm{e}}-k_{1} t
$$

where $q_{\mathrm{e}}\left(\mathrm{mg} \mathrm{g}^{-1}\right)$ is the number of MB molecules absorbed onto the absorbent at equilibrium, $q_{t}\left(\mathrm{mg} \mathrm{g}^{-1}\right)$ is the amount absorbed at time $t$ and $k_{1}\left(\mathrm{~min}^{-1}\right)$ is the rate constant of pseudofirst-order adsorption that can be calculated from the slope of linear plot of $\ln \left(q_{\mathrm{e}}-q_{t}\right)$ versus $t$.

The linear kinetic equation of pseudo-second-order can be given as follows: ${ }^{17}$

$$
\frac{t}{q_{t}}=\frac{1}{k_{\mathrm{ps}} q_{\mathrm{e}}^{2}}+\frac{t}{q_{\mathrm{e}}}
$$

where $q_{\mathrm{e}}$ and $q_{t}\left(\mathrm{mg} \mathrm{g}^{-1}\right)$ correspond to adsorption capacities at equilibrium and time, respectively; and $k_{\mathrm{ps}}\left(\mathrm{g} \mathrm{mg}^{-1} \mathrm{~min}^{-1}\right)$ is the rate constant of pseudo-second-order adsorption equation that can be obtained by calculating the intercept of the linear equation.
The kinetic parameters, correlation coefficients $\left(r^{2}\right)$ and rate constant $(k)$, of pseudo-first-order and pseudo-second-order models, were calculated from eqn (3) and (4). As shown in Table 1 , the $r^{2}$ was more than 0.896 which indicated that the adsorption of MB by N-Fe NPs, O-Fe NPs and air-Fe NPs all suited the pseudo-second-order model. Compared to the pseudo-first-order model, the coefficient values for the pseudosecond-order model ranged from $0.89-1.00$ for the N-Fe NPs. This indicated that the sorption process mainly involved chemisorption. Meanwhile the rate constant also rose as $T$ increased (the range of $k_{2}$ was 0.03-48.24), implying the adsorption of MB may be an endothermic process, which further proved that temperature had a significant impact on the rate constant. The correlation coefficients $\left(r^{2}\right)$ of pseudo-firstorder in the range from $0.45-0.97$ for O-Fe NPs, were less than that of pseudo-second-order (the range of $r^{2}$ was 0.98-0.99), confirming that the sorption of MB onto O-Fe NPs fitted well with to the pseudo-second-order model.

However, the pseudo-first-order model can be also used to describe the adsorption process with O-Fe NPs comparing to $\mathrm{N}-\mathrm{Fe}$ NPs at $313 \mathrm{~K}$, implying the adsorption capacity of O-Fe NPs was stronger due to the contents of iron oxide nanoparticles. Furthermore, the adsorption capacity of air-Fe NPs may lie between N-Fe NPs and O-Fe NPs, which will be further proven by Langmuir isotherms models. The adsorption process of MB by various adsorbents has been reported previously ${ }^{11,17}$ Furthermore all the experimental data showed that the adsorption process of MB fitted well to the pseudo-second-order model, and it occurred through chemisorption rather than physical adsorption.

3.3.2 Reduction kinetics. The process of removing $\mathrm{MB}$ by Fe NP $\left(\mathrm{N}_{2}, \mathrm{O}_{2}\right.$ and air) includes not only chemical adsorption, but may also involve chemical reaction. Therefore, reduction

\begin{tabular}{|c|c|c|c|c|}
\hline \multirow[b]{2}{*}{ Temp (K) } & \multicolumn{2}{|c|}{$\begin{array}{l}\text { Pseudo-first-order } \\
\text { model }\end{array}$} & \multicolumn{2}{|l|}{ Pseudo-second-order } \\
\hline & $k_{1}\left(\min ^{-1}\right)$ & $r^{2}$ & $k_{2}\left(\mathrm{~g} \mathrm{mg} \mathrm{P}^{-1} \min ^{-1}\right)$ & $r^{2}$ \\
\hline \multicolumn{5}{|l|}{$\mathbf{N}_{2}$} \\
\hline 293 & 0.2055 & 0.7759 & 0.0261 & 0.8961 \\
\hline 298 & 0.0598 & 0.8900 & 1.8029 & 0.9987 \\
\hline 303 & -0.0261 & 0.4054 & 0.8343 & 0.9997 \\
\hline 313 & 0.0041 & 0.0100 & 48.3139 & 1.0000 \\
\hline \multicolumn{5}{|l|}{$\mathbf{O}_{2}$} \\
\hline 293 & 0.0521 & 0.4515 & 0.2584 & 0.9836 \\
\hline 298 & 0.0859 & 0.8493 & 0.1751 & 0.9876 \\
\hline 303 & 0.1003 & 0.8871 & 0.0462 & 0.9879 \\
\hline 313 & 0.0527 & 0.9751 & 0.0721 & 0.9990 \\
\hline \multicolumn{5}{|l|}{ Air } \\
\hline 293 & 0.0464 & 0.94 & 0.6589 & 0.9988 \\
\hline 298 & 0.0360 & 0.9012 & 0.9546 & 0.999 \\
\hline 303 & 0.0299 & 0.8317 & 0.1479 & 0.9588 \\
\hline 313 & 0.0949 & 0.952 & 1.4292 & 1.0000 \\
\hline
\end{tabular}

Table 1 Adsorption kinetics parameters for the removal of MB by Fe $\operatorname{NPs}\left(\mathrm{N}_{2} / \mathrm{O}_{2} /\right.$ air $)$ 
Table 2 Reduction kinetics parameters for the removal of MB by Fe $\operatorname{NPs}\left(\mathrm{N}_{2} / \mathrm{O}_{2}\right.$ /air $)$

\begin{tabular}{|c|c|c|c|c|}
\hline \multirow[b]{2}{*}{ Temp (K) } & \multicolumn{2}{|c|}{ Pseudo-first-order } & \multicolumn{2}{|l|}{ Pseudo-second-order } \\
\hline & $k_{1}\left(\min ^{-1}\right)$ & $r^{2}$ & $k_{2}\left(\mathrm{~g} \mathrm{mg} \mathrm{P}^{-1} \min ^{-1}\right)$ & $r^{2}$ \\
\hline \multicolumn{5}{|l|}{$\mathbf{N}_{2}$} \\
\hline 293 & 0.0085 & 0.7589 & 0.0035 & 0.8732 \\
\hline 298 & 0.0052 & 0.9039 & 0.0024 & 0.9179 \\
\hline 303 & 0.0058 & 0.8775 & 0.0105 & 0.8583 \\
\hline 313 & 0.0063 & 0.9252 & 0.0636 & 0.8971 \\
\hline \multicolumn{5}{|l|}{$\mathbf{O}_{2}$} \\
\hline 293 & 0.0027 & 0.7468 & 0.0006 & 0.7371 \\
\hline 298 & 0.0037 & 0.9174 & 0.0013 & 0.9576 \\
\hline 303 & 0.0107 & 0.9563 & 0.004 & 0.9668 \\
\hline 313 & 0.0405 & 0.9735 & 0.0424 & 0.9703 \\
\hline \multicolumn{5}{|l|}{ Air } \\
\hline 293 & 0.0014 & 0.9426 & 0.0004 & 0.9463 \\
\hline 298 & 0.0015 & 0.9685 & 0.0005 & 0.9670 \\
\hline 303 & 0.0243 & 0.8706 & 0.0188 & 0.7742 \\
\hline 313 & 0.0404 & 0.8668 & 0.1960 & 0.9617 \\
\hline
\end{tabular}

kinetics was investigated to further understand the removal process. Pseudo-first-order and pseudo-second-order models were provided as shown below: ${ }^{18}$

$$
\begin{gathered}
\ln \frac{C}{C_{0}}=-k_{\mathrm{obs}} t \\
\ln \left(\frac{1}{C_{t}}-\frac{1}{C_{0}}\right)=k t
\end{gathered}
$$

where $k_{\mathrm{obs}}$ and $k$ correspond to the pseudo-first and pseudosecond-order rate constants, respectively. $C_{0}$ and $C_{t}$ present the initial and instantaneous concentration of $\mathrm{MB}$ in aqueous solution at $t=0$ and $t=t$.

As shown in Table 2, with reference to the N-Fe NPs, values of the regression coefficients $\left(r^{2}\right)$ of the pseudo-second-order model ranged from 0.8583 to 0.8971 . However, the pseudofirst-order model indicated that regression coefficients $\left(r^{2}\right)$ ranged from 0.7589 to 0.9252 , illustrating the reduction process of MB fitted well to pseudo-first-order kinetics. Associated with the above finding, it can be concluded that the process of removing MB by N-Fe NPs may involve chemical reaction, due to there being much more zero-valent iron nanoparticles (nZVI) in N-Fe NPs than in O-Fe NPs, where the degraded products was proven by GC-MS analysis. Values of the regression coefficients $\left(r^{2}\right)$ of O-Fe NPs are demonstrated in Table 2. They range from 0.7468 to 0.9735 in the pseudo-first-order kinetic model and 0.9382 to 0.9703 for the pseudo-second-order kinetic model. It indicates that the pseudo-second-order model can describe the kinetic process more properly.

The removal of MB by O-Fe NPs was a more complicated process, as proven by SEM, there was a thick layer of iron oxide nanoparticles on the surface of O-Fe NP. Firstly, the MB molecules were transferred from liquid to solid via electrostatic interaction and $\pi-\pi$ interaction of species groups between adsorbate-adsorbent. ${ }^{19}$ Then, MB molecules were adsorbed into the interface of $\mathrm{O}-\mathrm{Fe}$ NPs due to the presence of adsorption sites. Lastly, adsorbed molecules that made contact with nZVI were then reduced by O-Fe NPs. Nevertheless, the restored strength was relatively weak because there was little nZVI content. Consequently, the results for reduction kinetics demonstrated that the degradation of MB by N-Fe NPs was more efficient than that of O-Fe NPs and air-Fe NPs.

\subsection{Adsorption isotherms}

To further analyze the process of adsorption, the Langmuir and Freundlich isotherm models were employed to fit the experimental data. The Langmuir adsorption isotherm assumes that adsorbents' surface sites are homogeneous and the adsorption process is a monolayer adsorption. It has been successfully used for describing the dynamic process of adsorption. The linear equation of the Langmuir model is given as follows: ${ }^{20}$

$$
\frac{C_{\mathrm{e}}}{q_{\mathrm{e}}}=\frac{1}{q_{\max } K_{\mathrm{L}}}+\frac{C_{\mathrm{e}}}{q_{\max }}
$$

where $C_{\mathrm{e}}\left(\mathrm{mg} \mathrm{L}^{-1}\right)$ is the equilibrium concentration of $\mathrm{MB}$ solution; $q_{\mathrm{e}}\left(\mathrm{mg} \mathrm{g}^{-1}\right)$ represents the amount absorbed at equilibrium; $q_{\max }\left(\mathrm{mg} \mathrm{g}^{-1}\right)$; and $K_{\mathrm{L}}\left(\mathrm{L} \mathrm{mg}^{-1}\right)$ corresponds to the maximum adsorption capacity and the Langmuir constant or equilibrium constant that can be calculated from the slope and intercept of the linear regression $C_{0} / q_{\mathrm{e}}$ versus $C_{\mathrm{e}}$.

The linear equation of the Freundlich isotherm, which is an empirical formula and describes the adsorption that takes place on the heterogeneous surface of an adsorbent, can be shown as follows: ${ }^{20}$

$$
\log q_{\mathrm{e}}=\log K_{\mathrm{F}}+\frac{1}{n} \log C_{\mathrm{e}}
$$

where $C_{\mathrm{e}}$ and $q_{\mathrm{e}}$ represent the equilibrium concentration of MB

\begin{tabular}{|c|c|c|c|c|c|c|c|}
\hline Parameters & \multicolumn{3}{|l|}{ Langmuir } & \multicolumn{3}{|l|}{ Freundlich } & $R_{\mathrm{L}}$ \\
\hline $\mathrm{O}_{2}$ & 28.3286 & 0.2822 & 0.9908 & 37.2992 & -21.367 & 0.2131 & $0.05-0.16$ \\
\hline Air & 28.7356 & 0.3207 & 0.9906 & 56.5588 & -6.8540 & 0.9613 & $0.04-0.46$ \\
\hline
\end{tabular}
in aqueous solution and the equilibrium adsorbed. $K_{\mathrm{F}}$ and $1 / n$ are the Freundlich constants, which relate to adsorption

Table 3 Isotherm parameters for the removal of MB by Fe NPs $\left(\mathrm{N}_{2} / \mathrm{O}_{2} /\right.$ air $)$ 

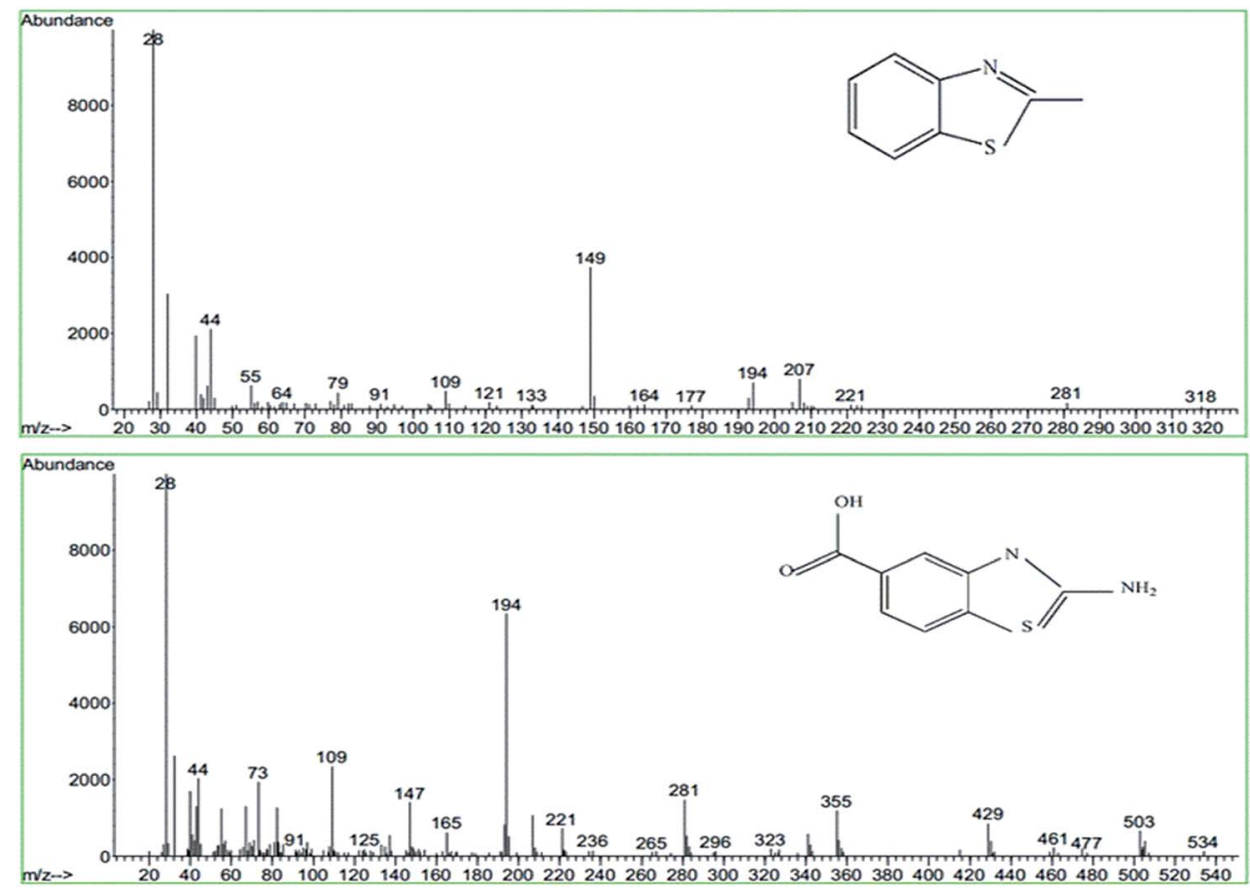

Fig. 4 Mass spectrometer of degraded products

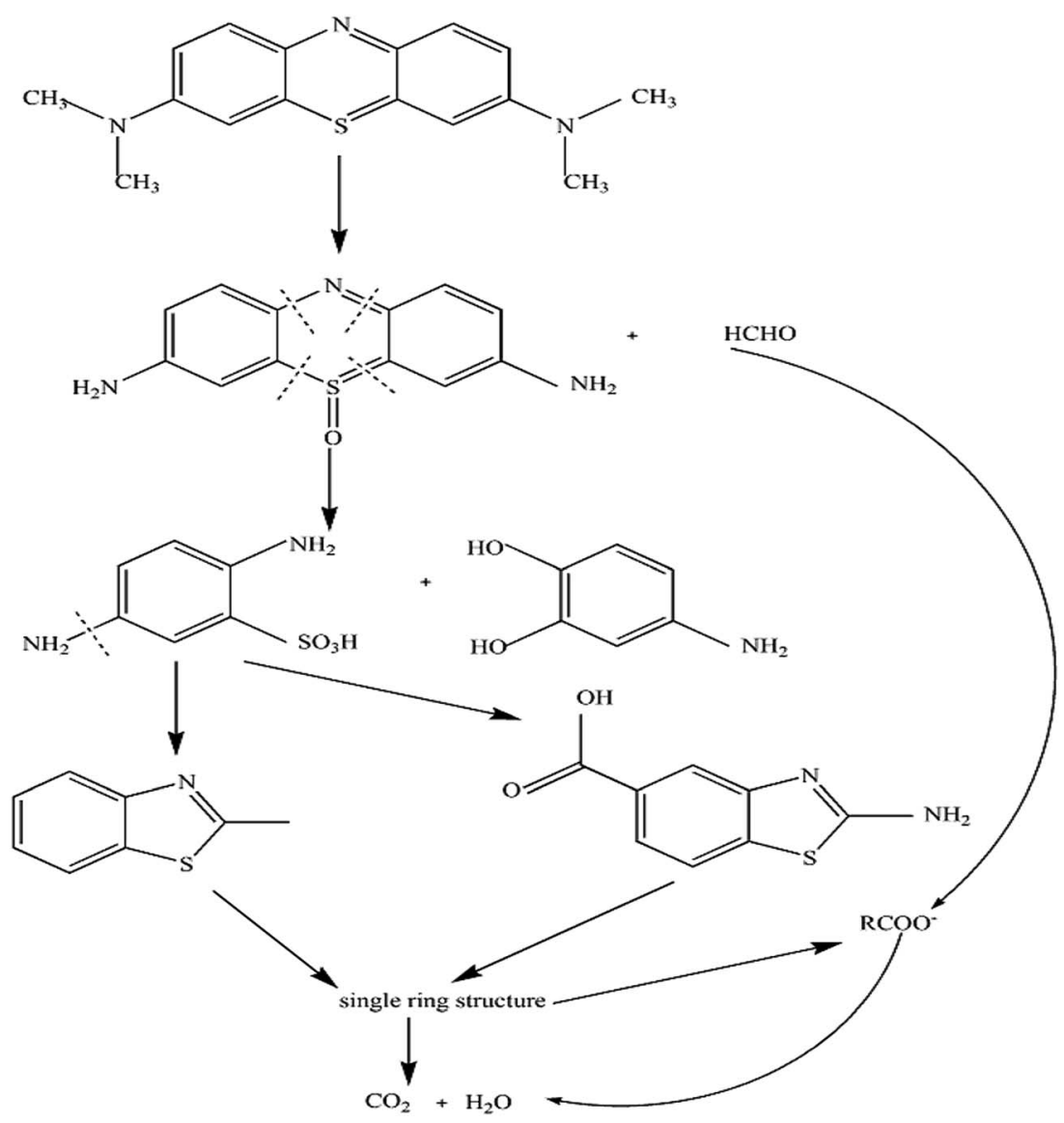

Fig. 5 The reduction degradation pathway of MB molecules. 
capacity and adsorption intensity, respectively. $K_{\mathrm{F}}$ was generally used to describe the strength of the relationship between adsorbate and adsorbent. ${ }^{21}$ The values of $n$ in the 1 to 10 range represent good adsorption, indicating that this process favored adsorption.

All the parameters values are summarized in Table 3 in terms of eqn (7) and (8). The adsorption isotherm is critical for investigating the adsorption system, which describes the correlation between adsorbate and adsorbent. As shown in Table 3, the $r^{2}$ values were all higher than 0.99, indicating the adsorption of MB by N-Fe NPs and O-Fe NPs fitted well to the Langmuir isotherm equation. The values illustrated that the $\mathrm{N}-\mathrm{Fe}$ NPs or O-Fe NPs' adsorption of MB was a monolayer process due to the homogeneous active sites on the surface of $\mathrm{Fe}$ NPs. The Langmuir adsorption isotherm equation hypothesized that the adsorbents' surface active sites were homogeneous and had identical energy. Furthermore the active sites were saturated when monolayer molecules were adsorbed onto the adsorbent surface. The maximum adsorption capacity $q_{\max }$ for MB onto N-Fe NPs and O-Fe NPs was obtained from the slope of the linear equation and the values shown in Table 3 were 52.910 and 28.329, respectively. Thus the adsorption strength of $\mathrm{N}-\mathrm{Fe}$ NPs for MB was higher than O-Fe NPs due to reduction of NZVI. The Freundlich exponents $\left(r^{2}=0.3897\right.$ and 0.2131, respectively) were less than that of Langmuir, confirming that the Freundlich adsorption isotherms model did not properly fit the MB adsorption process.

The values of dimensionless constant separation factor $\left(R_{\mathrm{L}}\right)$ can be calculated using the following equation, ${ }^{21}$ which is another essential parameter of the Langmuir isotherm:

$$
R_{\mathrm{L}}=\frac{1}{\left(1+b C_{\mathrm{i}}\right)}
$$

The results of $R_{\mathrm{L}}$ given in Table 3 were $1>R_{\mathrm{L}}>0$ for the adsorption of MB onto N-Fe NPs (in the 0.03-0.31 range) and O-Fe NPs (in the 0.05-0.16 range), demonstrating the adsorption process for MB was favorable. ${ }^{22}$

\subsection{Degraded products analysis}

The degradation products of MB using Fe NPs $\left(\mathrm{N}_{2}, \mathrm{O}_{2}\right.$ and air) were conducted by GC-MS analysis, and the results were shown in Fig. 4(a) and (b), respectively. A possible degradation pathway of MB using Fe NPs is illustrated in Fig. 5. Analogues of benzothiazole were detected in the degradation, a phenomenon that has been documented previously. ${ }^{23,24}$ As shown in Fig. 4, the signals at $m / z=149$ and $m / z=194$ correspond to intermediates after the structure of the MB molecules broken into smaller molecules components. As shown in Fig. 5, a possible degradation process is as follow. Firstly, $\mathrm{Cl}^{-}$is ionized in aqueous solution, then the loss of four $-\mathrm{CH}_{3}$ connected to $\mathrm{N}$ proceeds, which has a smaller bond dissociation energy (BDE) value in the $\mathrm{MB}$ molecular structure. ${ }^{23}$ Secondly, the $-\mathrm{CH}_{3}$ turns into $\mathrm{HCHO}$ or $\mathrm{RCOO}^{-}$. Thirdly, the $\mathrm{C}-\mathrm{S}$ and $\mathrm{C}-\mathrm{N}$ bonds in the middle ring which are the more active parts are broken into other small molecular weight intermediates. Finally, all the organic degradation products are transformed into $\mathrm{CO}_{2}$ and $\mathrm{H}_{2} \mathrm{O}$, and these may contain inorganic ions, such as $\mathrm{Cl}^{-}, \mathrm{SO}_{4}{ }^{2-}$ and $\mathrm{NO}_{3}{ }^{-}$in solution.

\section{Conclusions}

This study has demonstrated that green synthesis Fe NPs under various atmospheres $\left(\mathrm{N}_{2}, \mathrm{O}_{2}\right.$ and air) can be used to remove $\mathrm{MB}$ due to its reduction by $\mathrm{Fe}^{0}$ nanoparticles and adsorption on iron oxide nanoparticles. SEM and FTIR analyses showed that iron oxides were formed through the corrosion of $\mathrm{Fe}$ in oxygen and air atmosphere. Moreover, temperature had a significant influence on the removal of $\mathrm{MB}$. It indicated that the degradation process of MB by N-Fe NPs, O-Fe NPs and air-Fe NPs was an endothermic reaction. The investigation of kinetics demonstrated the degradation process of MB by N-Fe NPs fitted well to the pseudo-second-order adsorption and pseudo-firstorder reduction models. It was a chemisorption process rather than a physical sorption one. While the degradation process of MB using O-Fe NPs and air-Fe NPs seemed to fit well to pseudosecond-order adsorption and reduction kinetics. Meanwhile, the Langmuir isotherm model proved that the degradation reaction had a homogeneous and monolayer adsorption character. Finally, the degraded products obtained from MB reacting with Fe NPs were identified by GC-MS analysis, and a possible degradation pathway of MB using Fe NPs is proposed.

\section{Acknowledgements}

The authors thank the financial support given by the National Natural Science Foundation of China (No. 41401585).

\section{References}

1 S. Dutta, A. Bhattacharyya, A. Ganguly, S. Gupta and B. Srabanti, Desalination, 2011, 275, 26-36.

2 M. Iram, G. Chen, Y. P. Guan, A. Ishfaq and H. Z. Liu, J. Hazard. Mater., 2010, 181, 1039-1050.

3 T. X. Wu, N. T. Li, J. C. Zhao, H. Hidaka and N. Serpone, Environ. Sci. Technol., 1999, 33, 1379-1387.

4 A. Ghauch, A. Tuqan and H. A. Assi, Environ. Pollut., 2009, 157, 1626-1635.

5 Y. M. Lin, Z. X. Chen, Z. L. Chen, M. Megharaj and R. Naidu, Appl. Clay Sci., 2014, 93-94, 56-61.

6 X. L. Weng, L. L. Huang, Z. L. Chen, M. Megharaj and R. Naidu, Ind. Crops Prod., 2013, 51, 342-347.

7 S. Iravani, Green Chem., 2011, 13, 2638-2650.

8 L. L. Huang, X. L. Weng, Z. L. Chen, M. Megharaj and R. Naidu, Spectrochim. Acta, Part A, 2014, 117, 801-804.

9 Z. Q. Yu and S. S. C. Chuang, J. Phys. Chem. C, 2007, 111, 13813-13820.

10 Y. Bulut and H. Aydın, Desalination, 2006, 194, 259-267.

11 F. L. Fu, D. D. Dionysiou and H. Liu, J. Hazard. Mater., 2014, 267, 194-205.

12 H. I. Chieng, T. Zehra and B. L. L. Linda, Environ. Earth Sci., 2014, 46, 1-15. 
13 D. Kavitha and C. Namasivayam, Bioresour. Technol., 2007, 98, 14-21.

14 M. Auta and B. H. Hameed, Chem. Eng. J., 2011, 175, 233243.

15 P. Sharma and R. M. Das, J. Chem. Eng., 2013, 58, 151-158.

16 A. Roy, B. Adhikari and S. B. Majumder, Ind. Eng. Chem. Res., 2013, 52, 6502-6512.

17 M. Auta and B. H. Hameed, Chem. Eng. J., 2014, 237, 352361.

18 W. J. Jiang, C. Quan and X. Wei, Environ. Sci. Technol., 2014, 50, 1-27.
19 W. Chen, D. Lin and D. Q. Zhu, Environ. Sci. Technol., 2007, 41, 8295-8300.

20 S. Parimal, M. Prasad and U. Bhaskar, Ind. Eng. Chem. Res., 2010, 49, 2882-2888.

21 F. Tümsek and Ö. Avc1, J. Chem. Eng. Data, 2013, 58, 551-559.

22 Z. X. Chen, T. Wang, X. Y. Jin and Z. L. Chen, J. Colloid Interface Sci., 2013, 398, 59-66.

23 F. M. Huang, C. Li, H. L. Wang and Z. C. Yan, Chem. Eng. J., 2010, 62, 250-256.

24 B. Yang, J. N. Zuo, X. H. Tang and F. L. Liu, Ultrason. Sonochem., 2014, 21, 1310-1317. 